To the Editors:

\title{
Unacceptable teacher behaviour or medical student abuse?
}

Anxiety and its provoking factors during undergraduate courses have been a concern of many researchers. Issues such as examinations, dislocation from home environment, personal relationship problems and problems related to finances and accommodation have all been identified as factors responsible for anxiety [1].

We present data on certain aspects of teaching that provoke anxiety and adversely influence self-esteem of students. We conducted two surveys using anonymous self-administered questionnaires developed to describe the learning environment of students in the Faculty and teaching hospitals.

This preliminary survey was conducted in 2001 on a random sample of 41 final year students (from a batch of 174) immediately after completing their course in the Faculty of Medicine, Colombo (Group A1). The response rate was $70.7 \%$. The second survey was done in 2002 on final year students (Group A2), and among intern medical officers working in the Colombo group of hospitals (Group B). The latter consisted of 20 graduates from the Colombo Faculty (Group B1) and 42 from other Faculties of Medicine (Group B2). Responses were received from 124 from A2 and 62 from B (response rates were $70.8 \%$ and $69.7 \%$, respectively). The relevant results are tabulated (Table 1).

Table 1. Results of surveys

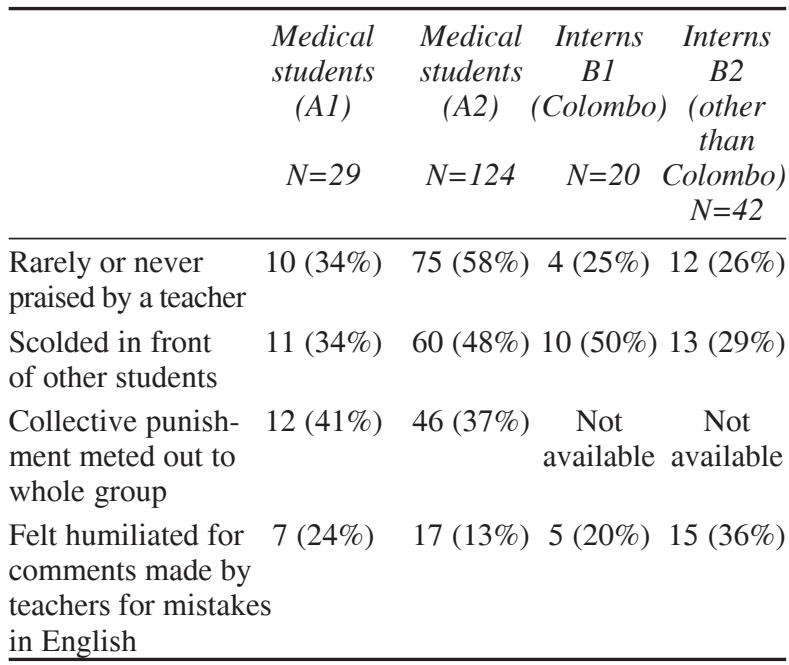

We were surprised by the manner in which medical teachers use punitive measures on adult learners. Such an authoritarian learning environment does not promote independent learning [2]. Punishment of a group of students for the fault of a few is unfair and against the principles of natural justice. Humiliation of students for making mistakes in English, which is not their mother tongue, is clearly unacceptable. The above behaviour of teachers could be defined as student abuse or bullying $[3,4]$

Medical schools have a duty and obligation to curtail such teachers' behaviour. A mechanism has to be in place to entertain complaints by students. If we do not take such an action, the solution may come from agencies outside the university system, for example, the Human Rights Commission or Sri Lanka Medical Council.

\section{References}

1. Kuruppuarachchi KALA, Kuruppuarachchi KAJM, Wijerathne S, Williams SS. Psychological distress among students from five universities in Sri Lanka. Ceylon Medical Journal 2002; 47: 13-5

2. Sobral De Jano T. Appraisal of medical students' diagnostic ability in relation to their learning achievement and self-confidence as a learner. Medical Teacher 2000; 22: $59-63$

3. Rosenberg DA, Silver HK. Medical student abuse. An unnecessary and preventable cause of stress. Journal of the American Medical Association 1984; 251: 739-42

4. Thompson D, Arora T, Sharp S. Bullying: Effective Strategies for Long-Term Improvement. London: Routledge Farmer, 2002

\footnotetext{
Saroj Jayasinghe, Associate Professor, Department of Clinical Medicine, Pubudu de Silva, Research Assistant, Damani de Silva, Senior Lecturer, Department of Psychological Medicine, Faculty of Medicine, University of Colombo. Correspondence: SJ, Tel:+94 1 2695300, email:<sarojoffice@yahoo.com> (Competing interests: SJ and $D$ de $S$ are medical teachers where the study was done). Received 8 August 2003 and revised version accepted 16 March 2004.
} 